\title{
O TERRITÓRIO E A (IR)RACIONALIDADE DA DECISÃO
}

JoÃo MORAIS MOURATO ${ }^{1}$

\begin{abstract}
Resumo - Este texto é um revisitar crítico da relação dinâmica entre os processos de criação de conhecimento e a sua utilização na dicotomia informação vs. validação de políticas públicas. Com enfoque na interacção entre os múltiplos agentes envolvidos na criação e utilização desse conhecimento reflectir-se-á, holisticamente, sobre a racionalidade que sustenta este universo de interacções e a forma como esta influencia os processos de tomada de decisão. Debater-se-á a existência de um estrangulamento comunicacional entre os múltiplos agentes de inovação e disseminação de conhecimento nos processos de elaboração e implementação de políticas públicas. Finalmente argumenta-se a necessidade da criação de amplificadores de comunicação institucional para desbloquear tal situação e catalisar uma mudança na forma como é encarada a relação conhecimento e território no contexto Português.
\end{abstract}

Palavras-chave: Conhecimento, poder, racionalidade, território.

\begin{abstract}
TERRITORY AND the (IR)RATIONALity OF DECISION. This paper constitutes a critical review of the dynamic relationship between knowledge creation processes and their usage in the "information vs. validation of public policies" dichotomy. By focusing on the interaction between all types of agents involved in these processes, a holistic reflection is undertaken that seeks to inquire into the rationality behind these interactions and the way in which it influences the decision-making processes. The existence of a communicational bottleneck in the design and implementation of public policies is highlighted. In order both to tackle this problem and to catalyze a change in the way in which the relationship between knowledge and territory is perceived in Portugal, a case is made for institutional communication amplifiers.
\end{abstract}

Key words: Knowledge, power, rationality, territory.

Résumé - Territoire eT L'(IR)RATIONALitÉ DE LA DÉCiSION. Ce texte discute la relation dynamique liant les processus de production de connaissance et son utilisation

Recebido: 29/09/2008. Revisto: 31/12/2008. Aceite: 05/01/2009.

1 The Bartlett School of Planning - University College London. E-mail: j.mourato@ucl.ac.uk 
dans la dicotomie information $v s$. validation de politiques publiques. En se fixant sur les multiples agents de cette connaissance, on s'engage à faire une réflexion holistique sur la rationalité qui soutient cet univers d'interaction et sur la façon dont elle influence les processus de décision. Finalement, on argumente la nécessité de créer des amplificateurs de communication institutionnelle pour débloquer cette situation et catalyser un changement dans la perception de la relation entre connaissance et territoire au Portugal.

Mots-clés: Connaissance, pouvoir, rationalité, territoire.

\section{INTRODUÇÃO}

O conhecimento é sinónimo de perspectiva de desenvolvimento socioeconómico para o Portugal do século XXI. A "economia do conhecimento" e sua companhia semântica, as políticas da inovação, pilares orientadores da Agenda de Lisboa, são forte influência na corrente agenda de desenvolvimento territorial nacional. Para Portugal, uma dinâmica evolutiva baseada no "conhecimento", traduz contudo um cenário à partida complexo. Não falta informação espelhando quer o deficit de formação associado a parte da nossa população activa contemporânea quer a falta de uma cultura de capitalização no "conhecimento", que não nos é nem indígena nem endógena. Sublinhe-se neste contexto que, apesar dos crescentes casos de sucesso e da ininterrupta dinamização de iniciativas especificamente direccionadas para o efeito desde os anos 90, o princípio da optimização e comercialização do "conhecimento" demora a generalizar-se na dinâmica organizacional/empresarial em Portugal. Estimular um posicionamento diferenciador na "economia do conhecimento" (independentemente do sector específico de actividade) depende fortemente da reflexão sobre a melhor forma de catalisar este tipo de mudança face à criação e utilização do conhecimento, mudança esta que é, na sua mais crua essência, de natureza "cultural"?.

Os desafios associados ao futuro do planeamento e ordenamento do território ${ }^{3}$ são, em larga medida, de natureza similar aos provocados pela economia do conhecimento. O conhecimento está no cerne da próxima década de evolução do sistema de planeamento e ordenamento do território português; seja (1) no processo de formação e informação dos agentes que o dinamizam e regulam, (2) na necessidade de assegurar um conhecimento transparente sobre o seu funcionamento (3) na evolução da forma como gerimos, disponibilizamos e capitalizamos o conhecimento que criamos sobre o território nacional, ou ainda (4) na utilização que o cidadão faz do conhecimento que lhe é disponibilizado sobre o território que ocupa.

2 Não sendo objectivo deste texto a revisão crítica do que significa cultura, entende-se para efeitos operativos que "a Cultura é (...) um fenómeno colectivo, (...) pelo menos parcialmente partilhado com as pessoas que vivem ou viveram dentro do mesmo ambiente social onde se deu o processo de aprendizagem. É a programação colectiva da mente que distingue os membros de um grupo ou categoria de pessoa de outros. A cultura é aprendida não herdada. Ela provém do ambiente social de cada um não de uma herança genética" (Hofstede, 1991:5).

3 Ao longo do texto será feita extensa utilização da expressão planeamento e ordenamento do território. Não se visa sugerir desta forma que o planeamento (natureza estratégica) e o ordenamento (natureza reguladora) são uma coisa só. Visa-se, sim, sublinhar que existe uma inevitável interdependência entre ambos, nomeadamente no contexto do tema abordado neste texto. 
Em suma, este texto centra-se na premissa de que é pertinente o revisitar do debate sobre a forma como se dá, em Portugal, a relação entre conhecimento e território. Nesse sentido este texto estruturar-se-á em três partes. Primeiro, argumentar-se-á sobre a existência de um ciclo discursivo/operativo interligando a criação de conhecimento, sua influência na evolução conceptual em políticas públicas e a mudança cultural/organizacional/cívica que daí poderá advir. Segundo, debater-se-á a(s) racionalidade(s) que $\operatorname{suporta}(\mathrm{m})$ a utilização desse mesmo conhecimento na informação e validação dos processos de tomada de decisão pública. Terceiro explorar-se-á a hipótese da existência de um estrangulamento comunicativo entre diferentes níveis de decisão, ou diferentes arenas políticas, como obstáculo ao efeito dinamizador do conhecimento na evolução e optimização do ciclo discursivo/operativo acima referido. Finalmente, concluir-se-á hipoteticamente sobre os possíveis efeitos de uma mudança na forma como é encarada a relação entre conhecimento e território. Embora este seja um texto na sua essência teórico, onde se enceta um exercício de sistematização conceptual, recorre-se pontualmente a exemplos empíricos para efeitos ilustrativos. Largamente baseados no caso do Reino Unido, estes permitem traçar raciocínios paralelos úteis para a exploração não só do tema do texto em si, como também para equacionar possíveis cenários evolutivos da cultura organizacional portuguesa.

\section{ENQUADRAMENTO CONCEPTUAL}

"The creation of knowledge in social networks is a key characteristic of the dynamics of culture ${ }^{4}$.

(CAPRA, 2003:88)

Em Portugal, independentemente dos "conflitos" inter e intra disciplinas/corporações profissionais sobre a detenção da autoridade científica/profissional sobre certos "sectores de conhecimento", há sem dúvida uma "cultura" de interpretação/sustentação científica da nossa interacção socioeconómica com o território. O ponto de partida é o pensar em possíveis cenários evolutivos dessa "cultura". À partida discutir "conhecimento" requer o assumir de todo um universo de interacções entre agentes criadores, dinamizadores, supressores, influenciadores e utilizadores desse mesmo conhecimento. Um sistema de planeamento e ordenamento do território é um palco político/organizacional onde é lógico reflectir sobre estas interacções. Como ponto de partida, e numa leitura estruturalmente simplificada, o seguinte diagrama (fig. 1) introduz o que se propõe denominar, para efeitos de discussão, como o ciclo discursivo/operativo do sistema. Este ciclo resulta do processo de inovação conceptual, perpetuação, gestão e circulação de conhecimento que suporta o funcionamento e evolução desse mesmo sistema.

4 "A criação de conhecimento nas redes sociais é uma característica chave das dinâmicas culturais" (Tradução do autor). 


\section{Ciclo Discursivo / Operativo}

Dinâmicas de Influência

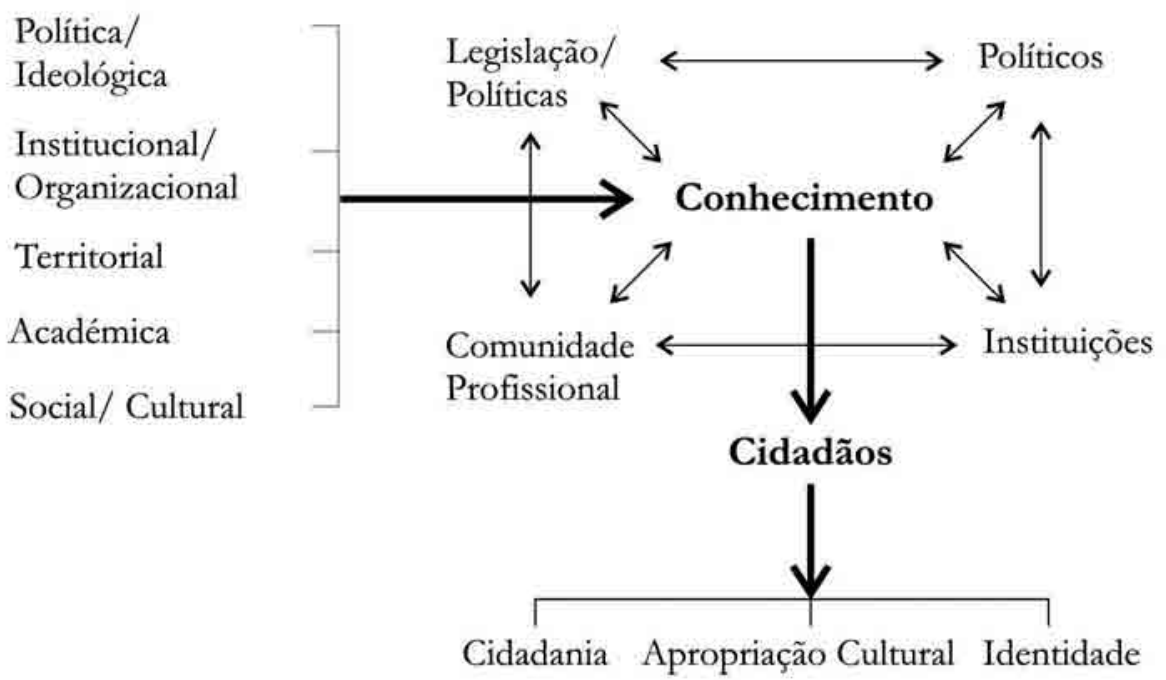

Fig. 1 - Ciclo Discursivo/Operativo.

Fig.1 - Discursive/Operative Cycle.

O ponto focal de análise proposto é o entender como o conhecimento inserido no sistema influencia as alterações comportamentais dos actores e instituições nele envolvidos, dos políticos que o regulamentam e dos cidadãos que o utilizam. Por outras palavras, mais do que as especificidades técnicas do conhecimento em si, o que se visa analisar é o seu posicionamento, transformação e natureza de interacções no ciclo discursivo/operativo acima referido. A título de exemplo, não é relevante qual o fundamento racional da noção de "policentrismo" como modelo de desenvolvimento territorial. Relevante, neste contexto, é sim, debater e perceber como o conceito de "policentrismo" é introduzido no sistema, como é influenciado, aceite ou deturpado pelo discurso político, políticas e legislação nacionais, como é discursivamente verbalizado por instituições e comunidade profissional e, finalmente, como é apropriado, se de facto o é, pelos decisores locais e cidadãos. Por outras palavras, são os mecanismos que suportam a transição da teoria à prática.

Ao exemplo do policentrismo podem ser facilmente adicionados outros (democracia deliberativa, governança, participação, sustentabilidade, regeneração, justiça social, etc.). A riqueza semântica propagada pela multidisciplinaridade científica e transversalidade disciplinar que os estudos do território crescentemente incorporam é terreno fértil para discutir a forma como a apropriação e deturpação conceptual convivem, por vezes, lado a lado dentro do sistema.

Sublinhe-se na leitura do diagrama (fig. 1):

- a multiplicidade de dinâmicas de influência catalisadoras de mudança ou inovação conceptual, quer externas quer internas ao sistema. De naturezas potencialmente 
diversas, estas determinam em larga medida o que é considerado como conhecimento, a codificação desse conhecimento assim como quem participa na sua formação e introdução no ciclo discursivo/operativo e consequentemente no sistema;

- a inexistência de agentes exclusivamente catalisadores ou meramente reactivos. De facto, inovação e mudança conceptual podem tanto ter origem num ponto específico do sistema, como resultar da interacção entre diferentes "partes" do mesmo. O mais comum será de facto encontrarem-se múltiplas dinâmicas sobrepostas. Pese embora os estrangulamentos comunicacionais existentes (Ferrão, 2007), políticos, políticas, legislação, instituições e comunidade profissional constituem uma rede interdependente de influências mútuas, tornando muito complexa, senão impossível, a dissociação de um qualquer destes elementos do seu enquadramento funcional. Recordemos, a este propósito, uma variedade de abordagens sociológicas que procura interpretar esta mesma interdependência em outros contextos; assim, se no diagrama substituíssemos a palavra conhecimento pela palavra sociedade e se pensássemos no conceito de Agência de Giddens (1986), de Poder de Foucault (1991) ou Flyvbjerg (1998), da teorização da Prática de Bourdieu (1992), do Novo Institucionalismo de Powell e Di Maggio (1991) todos avançariam em larga medida interpretações das "lógicas" de articulação entre os elementos do aqui denominado ciclo discursivo/operativo.

- a noção de que a apropriação do conhecimento inerente ao funcionamento do sistema por parte dos cidadãos a quem o sistema "em teoria" serve é condição sine qua non para a optimização da interacção cidadão/sistema. Será consensual assumir que é difícil, senão mesmo impossível, identificarmo-nos com aquilo que não conhecemos. Paralelamente, nem sempre se explicando porquê, generalizou-se nos discursos críticos ao sistema de ordenamento e planeamento do território a necessidade do reforço da interligação entre cidadão e território como uma dimensão significativa do exercício de cidadania. Se concordarmos com tal premissa, sai então reforçado o papel do conhecimento como veículo de apropriação dos valores culturais associados com a perspectiva de sociedade que almejamos e, consequentemente, com a fundamentação da identidade territorial dessa mesma sociedade ou, como sugere Fainstein (1996:27), mais do que a economia é a cultura que constitui a raiz da identidade.

- a ideia de que estes ciclos são ininterruptos, de que a mudança é algo incremental e, por vezes, não linear, permitem assumir que diferentes "partes" do sistema podem vir a ter papéis diferentes, consoante a fase de apropriação de um determinado conceito.

No entanto, uma questão é a estrutura do sistema, outra é o seu funcionamento, ou seja, é possível saber que "peças" existem no sistema e não perceber como elas interagem. O diagrama anterior (fig. 1) sugere uma matriz de interacção entre conhecimento e os restantes elementos do ciclo discursivo e operativo do sistema. A questão que se segue será a de reflectir, mais em pormenor, sobre as características e condicionantes que caracterizam a forma como o conhecimento influencia o sistema, se de facto o faz.

\section{Ciclo racional/ideal versus ciclo real}

Sugere-se, como ponto de partida, um diagrama-hipótese (fig. 2) que propõe, para efeitos de discussão, "um" ciclo de evolução conceptual em políticas públicas: 


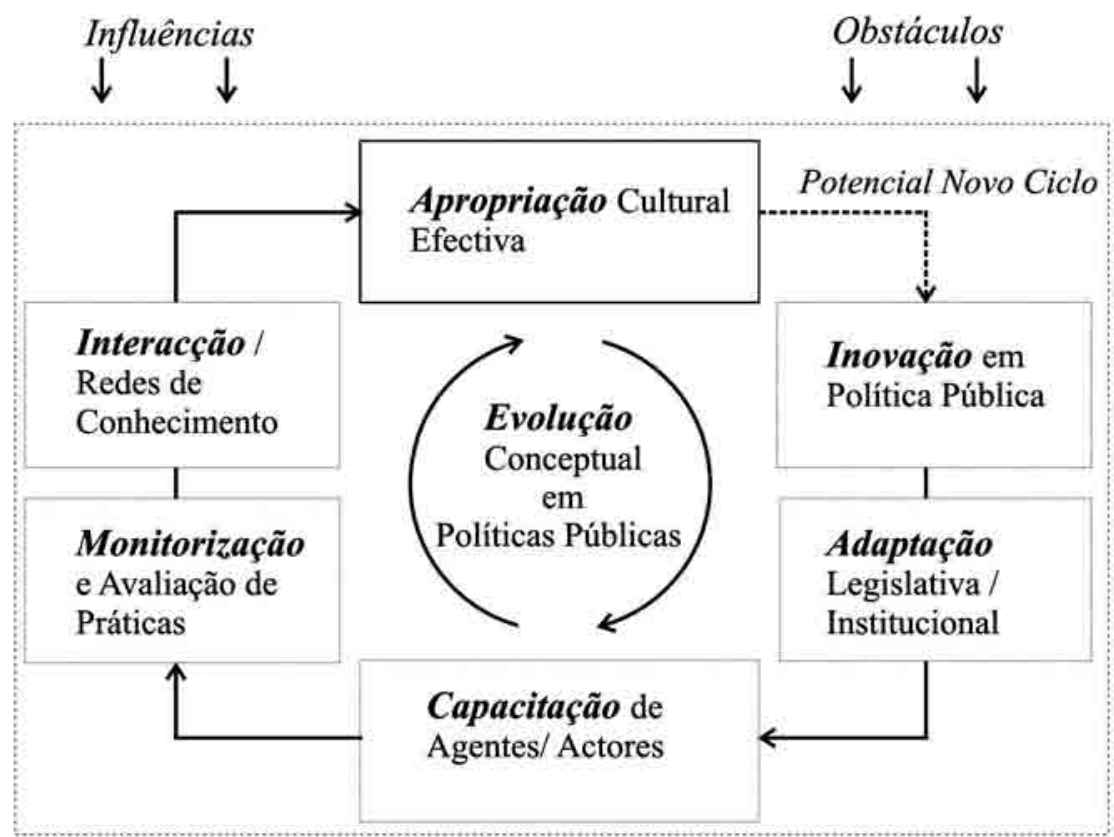

Fig. 2 - Evolução conceptual em políticas públicas - diagrama-hipótese.

Fig. 2 - Conceptual evolution in public policies - hypothetical diagram.

De certo modo, a interpretação da evolução conceptual do sistema transparece como um processo de aprendizagem de uma nova linguagem ou código comunicacional. Dentro de uma multiplicidade de leituras possíveis sugere-se a interpretação deste ciclo de mudança em três fases:

1. Catalizar: Inovação e Adaptacão (fig. 2) associam-se, neste contexto, à introdução no sistema de um estímulo à potencial mudança do mesmo. O impacto que este estímulo terá depende muito do equilíbrio relacional entre as influências e obstáculos que condicionam o processo de formulação e implementação de políticas públicas.

2. Operacionalizar: Capacitação, Monitorização/Avaliação. Metaforicamente, poder-se-á resumir que se trata da construção da arquitectura operacional do(s) conceito(s) que se visa(m) introduzir.

3. Mudar Culturalmente: Interacção e Apropriação são, em larga medida, os resultados práticos dos catalizadores e do processo operacionalizante acima referidos ao nível da socialização e mudança comportamental dos actores. Não será, contudo, imediato determinar quando se dá, se de facto se dá, a apropriação cultural dos conceitos introduzidos.

Contudo, a projecção acima apresentada deste ciclo de evolução conceptual assemelha-se, em larga medida, a um modelo estritamente racional e linear de criação de políticas públicas (Goss, 2001). Por outras palavras, representa um processo aparentemente ordeiro, com uma sequência lógica de passos que na sua totalidade servem o propósito final, neste caso a apropriação cultural efectiva. Este dispor ideal das peças 
constituintes do processo em causa encontra-se longe do processo real em que se dá, de facto, a apropriação cultural. Logo, para que se entenda a forma como o processo de apropriação, ele próprio, pode acarretar uma influência modeladora sobre o conhecimento em si, introduz-se agora uma possível interpretação real do ambiente em que o referido processo toma lugar. (fig. 3)

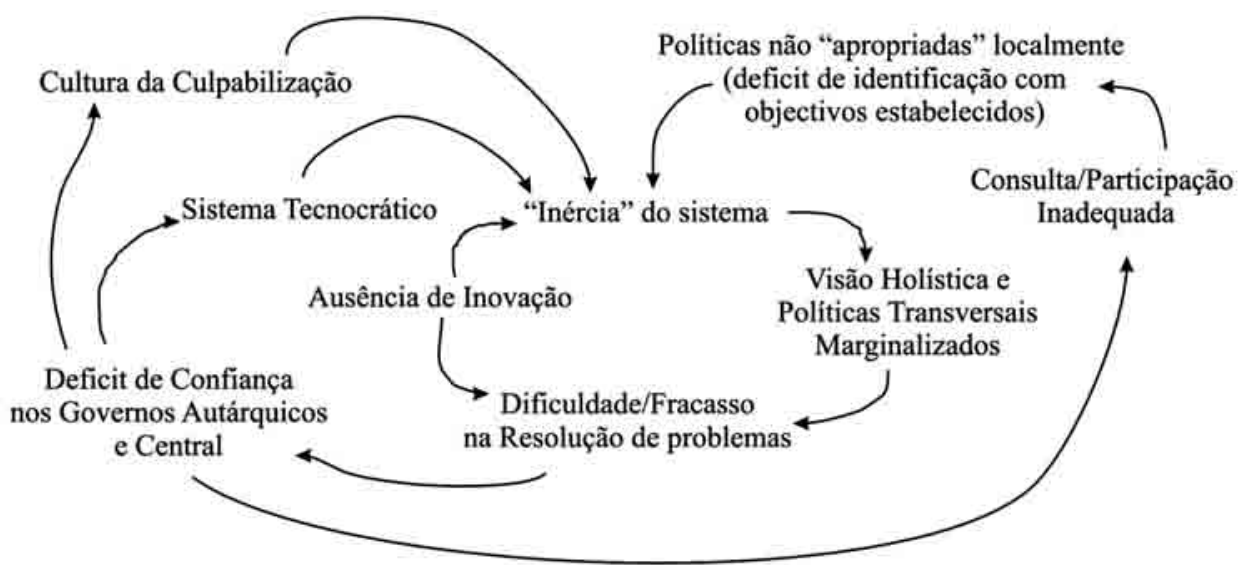

Fig. 3 - Sistema real (adaptado de Goss, 2001).

Fig. 3 - Real system (adapted from Goss, 2001).

A percepção do funcionamento real do sistema ilustra as limitações inerentes ao debate dos ciclos racionais de implementação de políticas públicas, ou da evolução conceptual das mesmas. O diagrama permite um leque variado de leituras, explicações e justificações, consoante o ponto que se escolha como "âncora" de raciocínio. Na lógica deste texto exploremos no sistema real (fig. 3) a questão da ausência de inovação. No seu sentido mais imediato (independentemente do sector específico de actividade) a inovação pode entender-se como a acção de operacionalização de um conjunto de regras e procedimentos distintos daqueles correntemente existentes, aos quais é associada, uma expectativa "instrumental" na resolução de problemas previamente diagnosticados. Instrumental no seu delinear, o papel do "conhecimento", como catalisador de mudança, é central à noção de inovação. Faça-se contudo uma ressalva importante. O "conhecimento" que aqui se discute não tem de ser, forçosamente, conhecimento "novo". Conforme sublinhava Schumpeter, por vezes, este existe já no sistema; o que é inovador é a forma como ele passa a ser encarado e utilizado. Reflictamos então, em pormenor, sobre a origem e utilização do "conhecimento" no processo de criação e informação de políticas públicas. 


\title{
III. QUE CONHECIMENTO PARA QUE PLANEAMENTO?
}

\section{1. "Conhecimento" e Políticas Públicas}

\begin{abstract}
"It is a matter of borrowing and copying bits and pieces of ideas from elsewhere, drawing upon and amending locally tried and tested approaches, cannibalising theories, research trends and fashions and not infrequently flailing around for anything at all that looks as if it might work. Most policies are ramshackle, compromise hit-and-miss affairs, that are reworked, tinkered with, nuanced and inflected through a complex process of influence, text production, dissemination and, ultimately, recreation in contexts of practice 5 ".
\end{abstract}

(BALL, 1998:126)

A visão de Ball sobre o processo de criação e informação de políticas públicas provoca no mínimo, reflexão. A génese de uma política pública, tal como "todos os tópicos complexos, parece dissimuladamente simples à primeira vista" (Healy, 2002: 97). A multiplicidade de factores que tal processo envolve e a relação por vezes pouco clara entre conhecimento, política e poder, podem estar na raiz desta complexidade. Para efeitos de raciocínio, sistematize-se "a utilização do conhecimento", na dicotomia forma vs. função. Embora fosse válido discutir a existência de uma dinâmica mutuamente influenciadora nesta dicotomia, centre-se a discussão no para que servirá o conhecimento criado (função) reservando-se para outro momento o debate sobre como servirá (forma). Em primeira instância, a essência da utilização do conhecimento na elaboração de políticas públicas está intimamente ligada à questão da validação política da sua existência. É sobre a racionalidade que assiste a esta validação que a presente secção se centrará.

As fundações da articulação entre a criação de conhecimento e a elaboração de políticas públicas no campo do planeamento e ordenamento do território são contemporâneas dos primeiros passos na construção dos sistemas de gestão territorial modernos no espaço Europeu. A título de exemplo, exploremos a evolução testemunhada no Reino Unido: neste contexto, em Londres, é uma referência histórica o diagnóstico dos problemas sociais da cidade levado a cabo por Charles Booth em 1887, diagnóstico este que veio a informar as leis da saúde pública e da habitação no final do século XIX, antecessoras do Town and Country Planning Act de 1947. A lógica "diagnóstico-pré-plano", o aforismo de Patrick Geddes "survey before plan" (Hall, 2002: 147) veio marcar fortemente décadas de evolução do sistema inglês e não só. Contudo, o enfoque deste tipo de análise informativa dava-se essencialmente nos aspectos físicos das cidades e regiões (Davoudi, 2006: 16) e não escondia algumas limitações que estariam, mais tarde, no centro do processo evolutivo do sistema de planeamento em si. Destas, sublinhemos três (Taylor, 1998: 66):

5 É uma questão de pedir emprestado ou copiar partes de ideias de outros, influenciando e corrigindo abordagens localmente experimentadas e testadas, canibalizando teorias, tendências e modas de investigação e não menos frequentemente procurar por tudo o que pareça funcionar. A maioria das políticas [neste contexto referindo-se ao planeamento e ordenamento do território] são periclitantes, re-trabalhadas, adulteradas, e transformadas através de complexos processos de influência, produção textual, disseminação e, em última instância, recriação em contextos de aplicação prática (Tradução do autor). 
- Não era sempre clara a razão da necessidade do diagnóstico, ou por outras palavras, nem sempre se debatia a definição do problema antes da recolha de informação. Os objectivos dos "planos" não estavam intuitivamente nas mãos dos políticos mas sim dos planeadores, que eram vistos como os peritos, apolíticos, guardiões do interesse público. Tal facto marca este período com percepções de cariz fortemente ideológico e mesmo visionário do que "deveria" ser a forma e ordem territorial e urbana ou, por outras palavras, não se planeava com a realidade planeava-se uma realidade onde tudo seria devidamente acomodado.

- O método Geddesiano baseava-se mais no conceito de plano único, ao invés de uma série de estratégias alternativas.

- Adicionalmente tomava-se como findo o processo de planeamento com a execução do plano propriamente dito. De facto, durante largas décadas a noção de actualização de conteúdos e monitorização do processo de implementação foi estranha ao planeamento e ordenamento do território no Reino Unido.

Contudo, durante a década de 50, foi incutido incrementalmente no "planeamento" um carácter cada vez mais multidisciplinar, fomentado em larga medida pelo relatório Schuster de 1948, que advogava a inclusão das ciências sociais no ensino do "planeamento" e a abertura da profissão de "planeador" a economistas, sociólogos e geógrafos (Davoudi, 2006: 17). Muito devido a estes últimos o "planeamento" viu-se exposto à lógica positivista, fomentada em larga medida pelas teorias de localização de Christaller, que propunha que o plano se devia basear-se, não somente em diagnósticos convenientemente mapeados, mas no desenvolvimento de hipóteses ou modelos de distribuição espacial que se poderiam testar ou comparar com a realidade e, consequentemente, reflectir sobre a sua validade. Este incorporar do método científico Popperiano na estrutura racional de acção do "planeamento" catalisou a revolução quantitativa que veio a eclodir nos anos 60 e 70. Esta mudança de paradigma caracterizou-se em traços gerais pela abordagem crescentemente sistémica das múltiplas dinâmicas existentes no território e pelo reforçar da validade do "planeamento" como um processo racional de tomada de decisão.

Em termos teóricos, tal traduziu-se na formação da dicotomia entre a teoria do planeamento substantivo, com enfoque no objecto, e a teoria do planeamento processual, com enfoque no próprio processo de planear (Faludi, 1973). A noção de sistema e sua correspondente teorização, com o rigor científico que lhe era associado, catapultou gradualmente a percepção do planeamento de "arte" para "ciência" fortalecendo a "fé na utilização da ciência na formulação de políticas públicas, não só como aplicação prática dos resultados da investigação científica, mas também em relação ao processo de formulação de políticas em si” (Taylor, 1998: 69). Neste contexto, o "planeador" seria um técnico qualificado que aconselharia o decisor político sobre as melhores formas de acção. Contudo, à medida que esta metodologia de sustentação científica à decisão ia sendo exposta a análise, compreendeu-se que o processo racional ideal de como as decisões "deveriam" ser tomadas dificilmente se comparava com a real forma incremental estando, por vezes, desarticulado com as decisões que eram de facto alcançadas (Lindblom, 1959). É exactamente esta discussão sobre a forma ideal e real de articular criação de conhecimento e tomada de decisão que se sugere revisitar de seguida. 


\title{
2. Decisão Ideal vs. Decisão Real?
}

\author{
"There is nothing a government hates more than to be \\ well-informed: for it makes the process of arriving at decisions \\ much more complicated and difficult" 6 . \\ (JoHn MAYNARD KeYNES)
}

O decisor político, num regime democrático estável e com relativa transparência funcional, está crescentemente em cheque. Com o início do século XXI testemunha-se uma reforma contínua dos meios de comunicação em muito resultante da generalização do uso das novas tecnologias e consequente celeridade de actualização e divulgação de informação em larga escala. Tal facto, poder-se-á argumentar, "força" um aumento da transparência processual e justificativa ao nível da decisão governamental. Paralelamente, o número de actores directa e indirectamente envolvidos nos processos de decisão tende também a aumentar. Estes dois factores, em conjunto, muito contribuem, ou poderão contribuir, para um multiplicar das formas de escrutínio contínuo da "decisão" política por parte dos media e da sociedade civil em geral. Não querendo debater a validade e as implicações éticas de todas estas formas de observação não se pode deixar de concordar que este enquadramento catalisa uma dinâmica crescente ao nível governamental para se solidificarem decisões políticas numa fundamentação de cariz científico. Assim, a par dos "profissionais (que) procuram evidências para justificar o seu conselho aos políticos, os políticos procuram evidências que suportem as políticas que eles desejam implementar" (Healy, 2002: 98) ou, dirão os mais pragmáticos, fazer parecer que assim o é.

Esta necessidade de validação pode, à partida, aliciar o decisor político a ter uma visão meramente linear e instrumental do que é, exactamente, a investigação e criação de conhecimento no processo de elaboração de políticas públicas. Tal facto pode promover a desarticulação entre o conhecimento real e ideal e gerar formas distintas de gestão da relação entre conhecimento e decisão (Davoudi, 2006:14), o que nos remete para a inevitável questão do Poder (Flyvbjerg, 2002: 353).

Academicamente, e ao contrário da ciência política ou da sociologia, o planeamento, como arena de acção sóciopolítica que é, não tem ainda um corpo central de estudos sobre as relações de Poder que incorpora. Friedmann (1987) sublinha a nossa ambivalência sobre o Poder, onde por vezes ao invés de debatermos o Poder no contexto do que realmente acontece na prática remetemo-nos para uma discussão ad eternum sobre o que normativamente e idealmente deveria acontecer. Este debate não é recente; para além de Flyvbjerg (1998), Hajer (1995) ou Jensen e Richardson (2000) também a escola de Planeamento Comunicacional de Forrester (1989) e Healey (1997) abordam a questão do Poder. No entanto, é possível argumentar que a racionalidade comunicativa, como Habermas a pensou, sustentada por estes últimos autores segue uma tendência demasiado "normativa e processual sem um entendimento substancial da Realpolitik e real racionalidade" (Flyvbjerg, 1998) inerente a estes processos. Para uma leitura mais descodificada deste debate, o que se sugere, em seguida, é uma breve narrativa interpretativa do que se passou, na primeira década do século XXI, no Reino Unido.

6 "Não há nada que um governo odeie mais do que estar bem informado: pois isto transforma o processo de tomada de decisões muito mais complicado e difícil" (Tradução do autor). 


\title{
3. Instrumentalizar o conhecimento
}

\author{
"This Government expects more of policy-makers. More \\ new ideas, more willingness to question inherited ways of \\ doing things, better use of evidence and research in policy- \\ making and better focus on policies that will deliver long term \\ goals."7
}

(CABinet OfFice, 1999)

Com a chegada ao poder, em 1997, do New Labour de Tony Blair, iniciou-se um ciclo de mudança na relação entre a criação de conhecimento e a informação de políticas públicas. Contrastando com o que se passava, e passa ainda, nos Estados Unidos da América, onde as "políticas públicas têm sido concebidas, debatidas e avaliadas através das lentes das (diferentes) ideologias" (Urban Institute, 2003: 1), no Reino Unido ganhou peso o denominado "evidence-based planning". Tal, segundo Davoudi, traduziu-se em termos práticos, no final dos anos 90, num aumento significativo em termos de orçamentos e efectivos dedicados à investigação a todos os níveis governamentais. Paralelamente, ao nível do espaço comunitário Europeu, a Comissão Europeia, talvez como forma de reforço e validação do seu peso político perante o conjunto dos Estados-membros, mostrou-se, ela também, receptiva a semelhante abordagem. Tal traduziu-se, não na criação do European Spatial Planning Observatory Network (ESPON), com enfoque na investigação sobre as políticas públicas com impactos territoriais como, de uma forma geral, pelo sublinhar, no seu White Paper on Governance, que "ciência e peritos desempenham um papel incrementalmente significativo na preparação e monitorização de decisões" (CEC, 2001: 428).

Para melhor compreender este ciclo de mudança, exploremos a estrutura racional por detrás de tal abordagem no Reino Unido, exemplo na sua essência semelhante ao cenário contemporâneo português. Solesbury (2002) avança duas interpretações distintas: por um lado, o objectivo por parte do New Labour de fomentar um cariz mais pragmático no seu modelo de governação, ao invés de um posicionamento mais ideológico, reflectindo assim uma mudança na natureza do fazer Política em si que se verifica por todo o espaço político Europeu contemporâneo. Por outro lado, tal abordagem reflectia a relação conhecimento-poder que o New Labour desejava impor, sublinhando a relação novo poder/nova agenda/novo conhecimento, validando os políticos do executivo governamental que queriam desafiar as influências "entrincheiradas", nomeadamente ao nível dos quadros da administração do Estado. Tal traduzia a suspeita de "influências exercidas sobre a formulação de políticas, particularmente dentro do Civil Service e a intenção de abrir a criação de políticas a elementos externos à administração" (Solesbury, 2002: 93).

Analisando criticamente esta interpretação, Davoudi (2006: 14) nota que, embora traduza, numa primeira análise, a máxima de Francis Bacon knowledge is power, (conhecimento é Poder), não deixa de sugerir que o oposto, power is knowledge (Poder é conhecimento), é também verdade pois, como enuncia Foucault, o Poder produz conhe-

7 "O governo espera mais dos "policy makers". Mais novas ideias, maior determinação para questionar formas herdadas de fazer coisas, melhor uso das evidências e da investigação na elaboração de políticas públicas e maior enfoque em políticas que concretizem objectivos a longo prazo" (Tradução do autor). 
cimento, nomeadamente quando "o Poder determina o que conta como conhecimento" (Flyvbjerg, 1998:226). Ora, assumindo que as "políticas públicas são desenvolvidas e implementadas através do uso do Poder" (Solesbury, 2002: 95), que o "conhecimento cuidadosamente «manuseado»" é ainda mais poderoso (Healy, 2002: 98) e que "o conhecimento está sujeito a corrupção tanto quanto outras fontes de poder" (Solesbury, 2002: 95), resta-nos perguntar que tipo de conhecimento será este, que real validade terá?

\section{What matters is what works! O que importa é o que funciona!}

Numa primeira leitura há um fundamento lógico neste "chavão" político britânico do final dos anos 90, que impele intuitivamente a concordar com o mesmo: O conhecimento real parte da suposição que a relação entre informação recolhida e o processo de elaboração da política pública é, toda ela, um processo linear, directo, estanque a influências externas e livre de problemas. Neste contexto, da intitulada investigação aplicada, assume-se que, ou a investigação dirige a formação de políticas públicas ou, alternativamente, que a investigação segue a formação de políticas públicas (Davoudi, 2006: 15). Contudo, uma segunda leitura, mais em pormenor, sublinha as limitações desta abordagem, algo determinística, ao excluir da discussão, por exemplo, "o que funciona para quem, e em que circunstâncias" no processo de formação de políticas públicas (Leicester, 2002). É, aqui, nesta perspectiva de ciclo de influência fechado, que se revela a fragilidade desta abordagem, pois, como identifica Weiss (1977), esta é uma fórmula altamente selectiva, se não mesmo oportunista, em que, por exemplo, as áreas temáticas que não são identificadas como um "problema" pelos decisores políticos não são alvo de processos de recolha exploratória de informação. É nesta "lacuna" que habita a filosofia do tipo ideal de conhecimento.

Este tipo de conhecimento caracteriza-se por explorar um tipo de influência na criação de políticas públicas que se materializa em benefícios por vezes menos directos, estruturados em larga medida, numa lógica temporal de médio e longo prazo. A sua ênfase, como descreve Davoudi (2006: 16), não é a fundamentação científica de “chavões" políticos mas sim a criação de uma plataforma holística de entendimento das condicionantes que regem determinada temática. Ou seja, é necessário expandir a natureza da investigação em si. Tal poderá ser atingido promovendo o carácter descritivo, analítico, diagnóstico, teórico e prescritivo que a investigação poderá ter (Solesbury, 2002: 94), para além de uma simples utilização de carácter avaliativo. Até porque, à questão da avaliação estão associadas uma série de fragilidades. Note-se que, "por vezes, a avaliação é uma das obrigações associadas à colocação das políticas públicas em prática, não um desejo de aprendizagem e melhoramento e não raramente a avaliação é vista como um meio de justificar decisões após o evento" (Healy, 2002: 98). Assim, neste contexto o que se argumenta é que o processo de investigação e criação de conhecimento deverá servir não exclusivamente como ferramenta de resolução de problemas per se mas como uma contribuição para um discurso informado (Shulock, 1999: 241). Tal propósito remete-nos para uma variável imprescindível para que o mesmo se forme: o investigador ele próprio.

\section{Os bastidores do conhecimento}

Em termos gerais, o modelo de financiamento e a estrutura académica da investigação em Portugal difere actualmente do Reino Unido; contudo, há um potencial para- 
lelismo futuro que torna pertinente perceber o que mudou no perfil e na forma de acção do investigador social britânico. A crescente orientação "utilitária" dos principais financiadores teve como efeito colateral um crescente pragmatismo na atitude dos investigadores, um desejo não somente de observar, mas de interagir com a sociedade (Solesbury, 2002: 91); em particular refira-se o compromisso de tornar a investigação não só útil como utilizável (idem.). Tal fez a comunidade científica reflectir não só sobre a criação, mas também sobre a disseminação de informação como forma de maximizar a sua "utilização"; assim, a "disseminação do conhecimento é agora vista como sendo tão importante como a sua própria génese" (Healy, 2002: 98). Pese embora esta pressão, "inquéritos nacionais reflectem um declínio generalizado na confiança que o público tem nos cientistas" (Bloom e Weisberg, 2007).

De facto, as comunidades científicas, tradicionalmente organizadas como uma estrutura clerical baseada na fé inquestionável dos seus seguidores, estão, elas também, crescentemente em cheque. A evolução social resultante do crescente acesso à formação e à informação fomenta uma geração de "utilizadores" mais críticos, capazes de um escrutínio mais eficaz da informação produzida. A mudança do enquadramento em que se produz ciência, e das características do público para quem se produz ciência, incute gradualmente uma nova forma de articulação de múltiplos tipos de conhecimento. Ao mais tradicional Know How (a experiência prática do que funciona) adicionaram-se o Know What (o estado do Mundo comparativamente à temática em causa), o Know Why (causas e explicações) e finalmente o Know Who (contactos e redes) (Solesbury; 2002: 92). A própria noção de fonte de conhecimento tende a ser crescentemente questionada - repare-se a este propósito na expressão anteriormente introduzida, evidence-based planning.

O Oxford English Dictionary (OED, 1998) identifica evidence como o corpo de factos ou informação disponíveis, indicando se uma pressuposição ou credo é verdadeiro ou válido. Há aqui uma pista interessante, pois não se trata somente da questão da validade da informação, mas também da sua disponibilidade. Se perguntássemos a um profissional da área do planeamento e ordenamento do território quais as suas fontes de informação no contexto da sua actividade, obteríamos, sem dúvida, uma diversidade de respostas. Uma série de profissionais com uma série de fontes diversas pode constituir, à partida, um ambiente criativo do ponto de vista da génese de conhecimento in house; no entanto, um ambiente profissional em que a proveniência da informação que circula nem sempre é identificável, pode incorrer, com óbvio perigo, no lugar comum convencionado do "toda a gente sabe que..." cimentando a inclusão de informação por vezes errónea no sistema.

Adicionalmente, existe o problema da natureza do conhecimento dos círculos profissionais que se estende muito para além do que é explícito, situando-se tacitamente na cabeça de uma série de "investigadores" que desenvolvem a sua carreira, por exemplo, como funcionários públicos afectos a corpos institucionais cuja função principal não é a investigação. Este conhecimento perde-se, por vezes, entre processos de reforma profissional ou transferência destes "investigadores". Todo este debate é, contudo, estéril quando reparamos que o conceito de construção ideal de um "discurso informado" se confronta, em ultima instância, com um obstáculo paradoxal. Independentemente de a forma de criação de conhecimento ser real ou ideal, nada garante que este venha a ter uma influência efectiva no desenvolver de políticas públicas. 


\title{
5. Da decisão à aplicação: a influência dos obstáculos (in)evitáveis?
}

\author{
"The ideal policy process fails to recognize that evidence \\ is not the only contender for influencing policy ${ }^{8 "}$.
}

(WEISS, 2001: 286)

Num processo algo semelhante ao Programa de Reestruturação da Administração Central do Estado da República Portuguesa (PRACE), uma das avaliações ao White Paper on Modernising Government do Governo do Reino Unido sublinhava que "entrevistas revelaram a evidência anedótica de que pouca da investigação encomendada pelos departamentos (do Estado) ou mesmo outra investigação académica foi usada na elaboração de políticas públicas" (Cabinet Office, 1999: 36). Discutem-se afinal dois tópicos que embora interligados podem em larga medida ser analisados separadamente, (1) a natureza do processo de criação de conhecimento por um lado, e por outro (2) as características do seu processo de aplicação ou, por outras palavras, a forma como este conhecimento influencia, na prática, a elaboração de políticas públicas. Reflictamos um pouco mais sobre este último ponto.

A hipótese que aqui se apresenta é a da existência de um estrangulamento comunicativo (fig. 4) entre diferentes níveis de decisão ou diferentes arenas políticas se assim o entendermos. Este estrangulamento, representado no diagrama na sua forma vertical, pode ser também horizontal, quando se toma como exemplo a comunicação entre diferentes departamentos da administração pública. Assim, como referido anteriormente (fig. 3), todo o ciclo de evolução/inovação conceptual de políticas públicas dá-se num "ambiente" onde se contrabalançam influências e obstáculos ao seu desenvolvimento. É essencial sublinhar a importância que o fluxo comunicativo detém: na lógica de que não nos identificamos com aquilo que não compreendemos, este fluxo comunicativo é um contributo essencial para, através de um processo de apropriação cultural, despertar no cidadão uma identidade (territorial), potencialmente catalisadora do seu sentido de cidadania.

Reflictamos então sobre os obstáculos, ou elementos de interferência à aplicação do conhecimento ao processo de elaboração de políticas públicas: estes, de acordo com Weiss (2001:286), podem ser abordados como o conjunto dos quatro Is: (1) Ideologia, (2) Interesses, (3) Influências Institucionais e (4) Informação préexistente. Pese embora esta sistematização tenha sido elaborada com base no caso específico dos Estados Unidos é, contudo, passível de alguma generalização.

Ideologia - A discussão sobre quais as influências ideológicas, se as houve, que mais ou menos declaradamente marcaram a evolução do sistema de planeamento português é algo que requer um espaço de reflexão próprio. O que se pretende aqui sugerir é se é possível, ou não, identificar actualmente um contexto ideológico de referência no planeamento e ordenamento do território em Portugal. Para sumariar o debate conceptual sobre o que se entende por ideologia sugere-se, para este efeito, que se trata "de um conjunto de valores e crenças que influenciam e determinam a formulação de políticas públicas de tal forma que nenhuma recolha, análise e apresentação de informação

8 O processo ideal de elaboração de politicas públicas peca por não reconhecer que o corpo de factos e informação disponíveis não são a única influência presente (Tradução do autor). 


\section{Estrangulamento Comunicativo?}

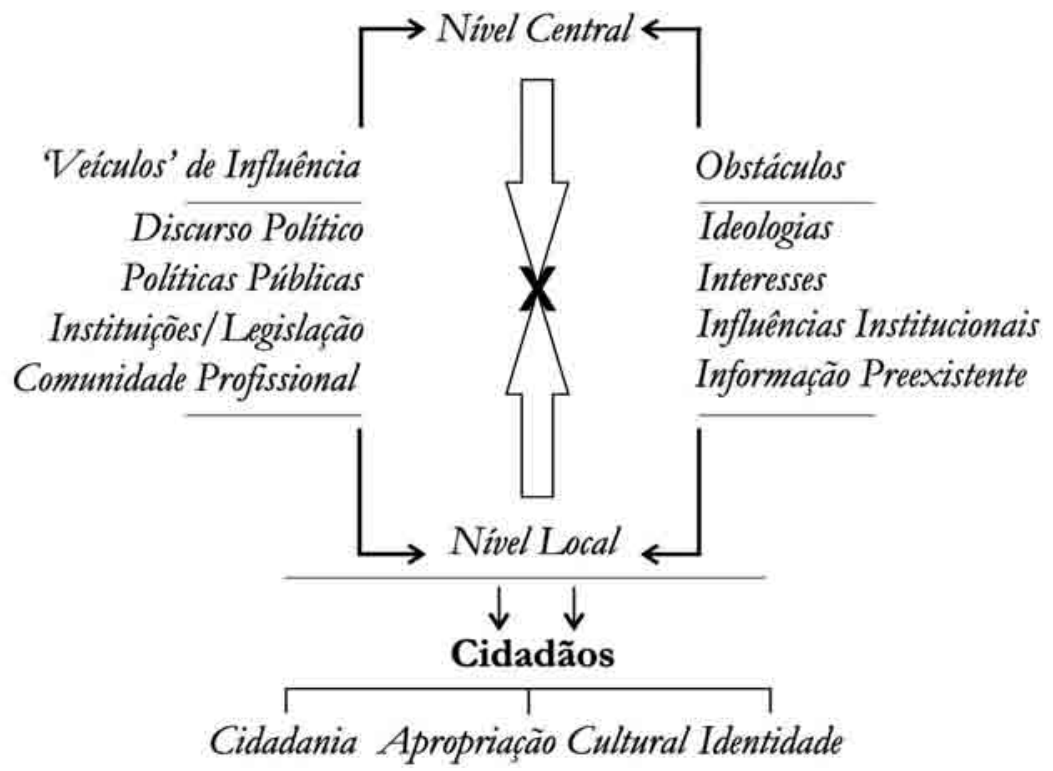

Fig. 4 - Estrangulamento Comunicativo.

Fig. 4 -Comunicative "Bottle Neck".

cientificamente validada as fará mudar". Poder-se-á argumentar que, contemporaneamente, será difícil reconhecer qualquer influência ideológica propriamente dita ou, pelo menos, como esta seria tradicionalmente identificada.

Poder-se-ia argumentar que a economia de mercado tem uma filosofia e agenda próprias mas terá em si uma ideologia? O que poderá ser mais facilmente consensual é que é possível encontrar exemplos ilustrativos da fragilidade deste equilíbrio entre razão/conhecimento que se enquadram na definição acima apresentada. Como pequena amostra repare-se neste episódio quase anedótico em que Böhme (2002: 101) relata uma apresentação pública feita por um consultor em representação do governo catalão sobre, na altura, a produção de um dos primeiros mapas de desenvolvimento regional da União Europeia. A apresentação intitulava-se $I$ want to be red in your map (eu quero ser vermelho no vosso mapa); tal traduzia bem o real interesse dos representantes regionais catalães que, independentemente do tópico específico em causa, queriam assegurar a cor vermelha para a sua região o que, por sua vez, implicaria maiores possibilidades de financiamento externo.

Interesses - Por interesses referimo-nos à vontade, legítima ou não, que indivíduos e organizações têm, e que podem subverter o uso da informação cientificamente validada. A manipulação de informação pode tomar corpo, por exemplo, como a necessidade de justificar a implementação de políticas públicas que foram já alvo de decisão. Davoudi (2006: 19) refere neste sentido o trabalho de Young et al. (2002) que denomina este processo como o "modelo político táctico da fundamentação científica" de políticas 
públicas. Neste contexto, as políticas públicas são suportadas por uma espécie de análise selectiva onde certos tipos de informação são utilizados e amplificados, enquanto outros são descartados ou minimizados. A natureza de certos "think-tanks" (centros de investigação não governamentais) prende-se fortemente com esta necessidade de fornecer legitimidade intelectual aos que governam (Denham e Garnett, 1996: 52).

Influência Institucional - Esta refere-se, em traços largos, às tradições culturais, organizacionais e ao capital humano das instituições chave no contexto do planeamento e ordenamento do território. Mais particularmente, sublinha-se a forma como as instituições agregam e articulam informação/investigação já existente, como a comunicam e como interagem com os agentes criadores de conhecimento. A influência institucional está directamente relacionada com a forma como cada instituição cria, acumula, articula, transfere, comunica e utiliza o conhecimento. Uma dificuldade adicional advém, por vezes, da sobrecarga de informação disponível em certas temáticas transdisciplinares. Esta requer a presença de utilizadores "inteligentes", que tenham a capacidade de compreender e interpretar essa informação. Ou seja, não se trata somente de trabalhar a chegada de informação às instituições, mas também de estruturar o processo interno de análise e tratamento da mesma, e, finalmente, das estratégias de divulgação interna e externa. Por divulgação externa entende-se mais do que simplesmente disponibilizar a informação ao público em geral. O principal "público-alvo" das instituições governamentais engloba políticos com e sem poder decisório, as comunidades profissionais e o corpo de funcionários dessas mesmas instituições. E esta linha comunicacional nem sempre é funcional como se pode ler do exemplo do Reino Unido, onde é "lugar comum que a vasta maioria dos muitos relatórios produzidos permanece largamente por ler, quer pela comunidade profissional quer por "policy-makers"” (Davoudi, 2006: 20).

Informação pré-existente - A existência de factos ou informação não é, por si só, garantia da sua influência na formulação de políticas públicas. Tal só acontece quando são "de facto" utilizados. Muita da resistência à utilização de informação, por vezes já disponível, prende-se com a ideia de que "hábitos velhos demoram a morrer". Ou seja, certas estruturas institucionais ou profissionais e a informação por elas produzida e veiculada tornam-se, de certa forma, obstáculos à evolução das políticas públicas que visam promover - dirão os mais cépticos que estas estruturas são mais uma arquitectura de manutenção do status quo do que plataformas de promoção da evolução do mesmo.

De facto, não é absurdo considerar que a evolução conceptual em políticas públicas tem tanto a ver com o encontrar da "verdade" e a optimização da resolução de problemas, como tem a ver com relações de poder e imposição de agendas políticas ou profissionais existentes no real contexto político-institucional (fig. 5), onde as diferentes fases da elaboração de uma política pública se dão. 


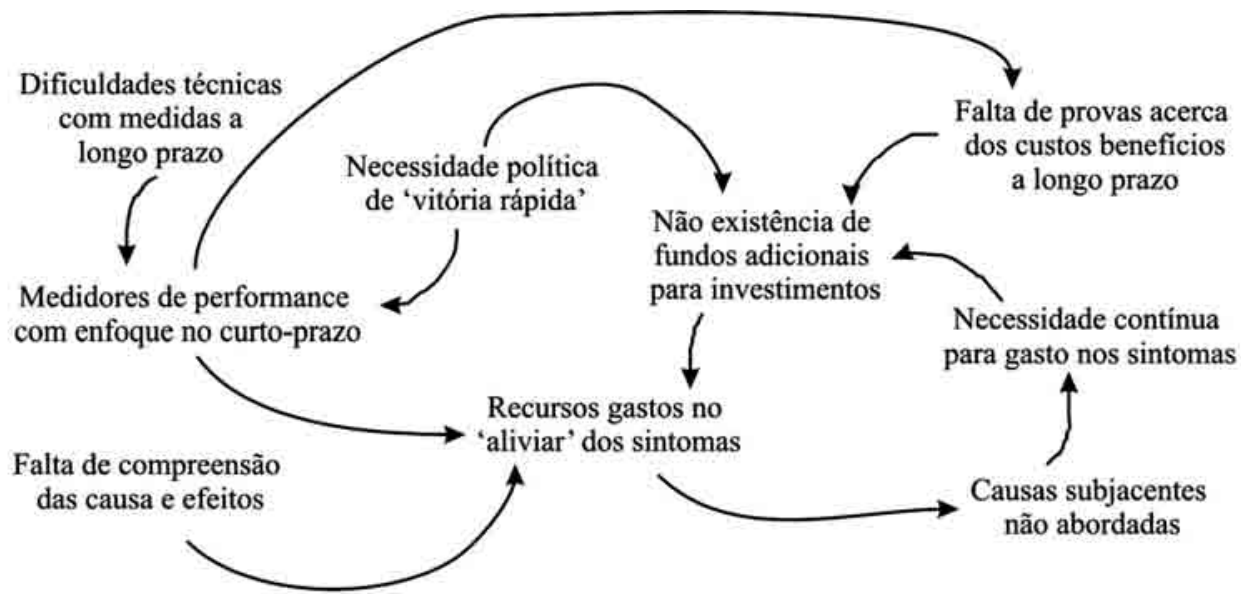

Fig. 5 - O real contexto político-institucional (adaptado de Goss, 1999).

Fig. 5 - The real political and institutional context (adapted from Goss, 1999).

\section{CONCLUSÕES}

Este texto tomou como ponto de partida a análise crítica da relação dinâmica entre os processos de criação de conhecimento e a sua utilização na informação e validação de políticas públicas. Argumentou-se a existência de um ciclo discursivo/operativo que resulta da interacção entre a criação de conhecimento, sua influência na evolução conceptual em políticas públicas e a mudança cultural/organizacional/cívica que daí poderá resultar. Explorou-se, através da distinção entre a natureza real vs. ideal do conhecimento, um conjunto de narrativas interpretativa(s) da(s) racionalidade(s) que sustenta(m) a utilização desse mesmo conhecimento na informação e validação dos processos de tomada de decisão pública. Finalmente, discutiu-se a existência de um estrangulamento comunicacional, entre diferentes níveis de decisão e arenas políticas.

Consciente de que não existe uma solução que por si só garanta a optimização do uso do conhecimento na evolução da elaboração e implementação de políticas públicas e impeça a interferência dos obstáculos antes identificados (Secção III.5.) sugere-se, contudo, a necessidade de maior cuidado na constituição e funcionamento do que se denomina, neste texto, como os amplificadores de comunicação (fig. 6). Por amplificadores de comunicação entendem-se os organismos institucionais ou agentes individuais que assumem uma importância crítica na disseminação da inovação conceptual que se insere no sistema. Esquematicamente: 


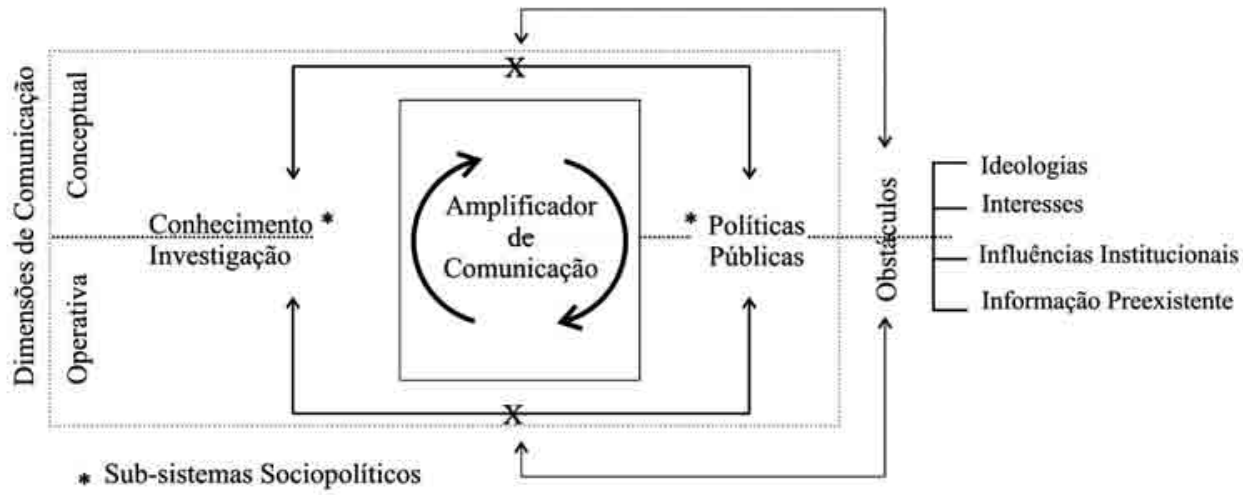

Fig. 6 - Amplificador de Comunicação.

Fig. 6 - Comunicational Amplifyer.

Sublinhe-se que esta disseminação não é somente distributiva, mas também explicativa. Não basta apenas garantir a produção e distribuição de conhecimento, mas também assegurar, através da interacção com os potenciais receptores dessa informação, que estes detêm capacidade para utilizar esse conhecimento. Assim, numa perspectiva geral:

$\operatorname{Re}(\mathrm{I})$ novação Conceptual e o Sistema de Planeamento e Ordenamento do Território

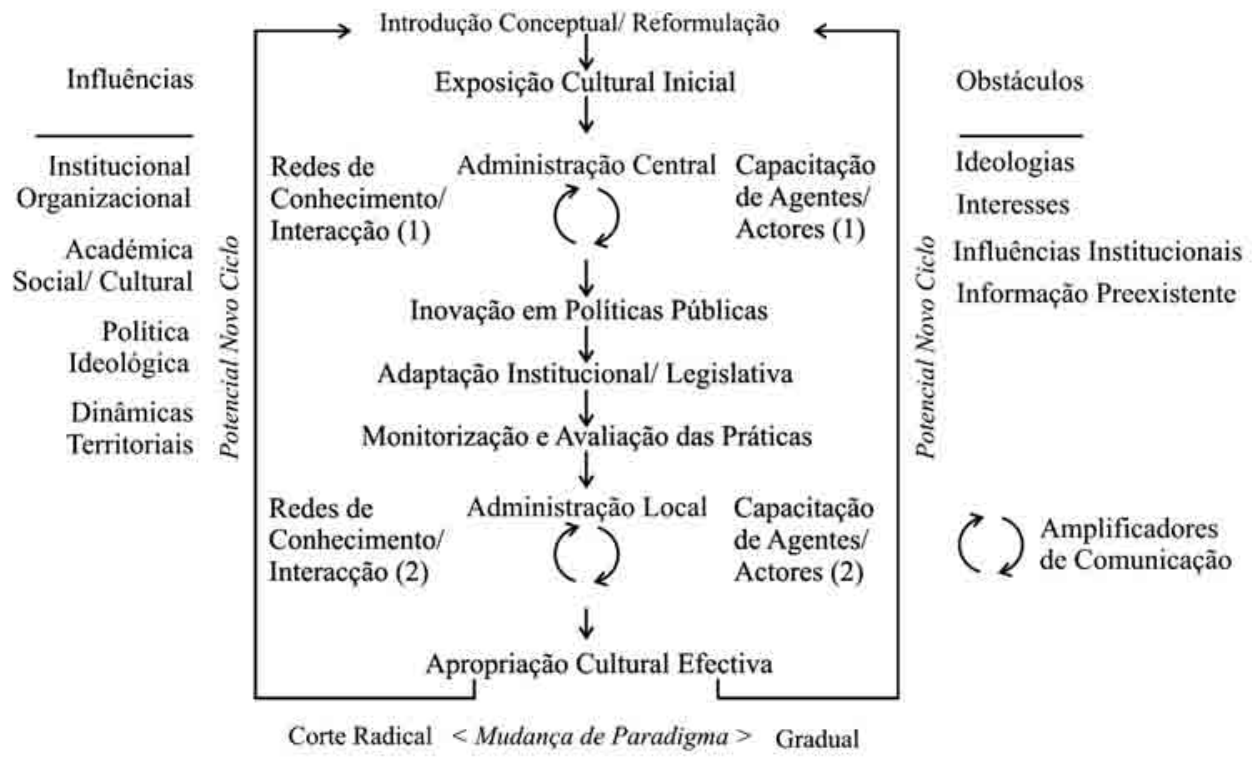

Fig. 7 - Re(I)novação Conceptual - Diagrama Geral.

Fig. 7 - Conceptual Re(in)novation - General Diagram. 
Saliente-se, também, que o conceito de amplificador de comunicação não implica forçosamente a constituição de uma nova arquitectura institucional, mas mais provavelmente um repensar das atribuições funcionais dentro do modelo existente (fig. 7). O momento é, de resto, propício a esta discussão, devido, por exemplo, à entrada em funcionamento do Observatório do Ordenamento do Território e Urbanismo. Este último detém todas as condições, do ponto de vista de uma filosofia operativa, para se poder tornar o amplificador comunicacional nato dentro do sistema de planeamento e ordenamento do território português. Em suma, este texto advoga a necessidade da criação ou promoção, ao longo do processo de criação e implementação de uma qualquer política pública, de amplificadores de comunicação que funcionem como garante da disseminação do conhecimento utilizado e da transparência processual. O objectivo não é somente a evolução conceptual na elaboração de políticas públicas e a crescente capacitação dos agentes envolvidos nos processos de gestão e desenvolvimento territorial, como também a afirmação da validade da política pública aos olhos do cidadão, facto que poderá implicar, por parte deste, o consequente reforço ou criação de um sentido de identidade territorial. O pressuposto subjacente é uma simples relação causal: não nos identificamos com o que não conhecemos.

\section{AGRADECIMENTOS}

Agradeço a Bas Waterhout, João Cravinho, João Ferrão, Mário Vale, Marta Vilar, Renato Carmo e Sérgio Caramelo e aos referees da revista Finisterra os comentários críticos e sugestões durante a elaboração e revisão deste texto cujas limitações são da minha total responsabilidade.

\section{BIBLIOGRAFIA}

Ball S (1998) Big policies/small world: an introduction to international perspectives in education policy. Comparative Education, 34(2): 119-130.

Bloom P, Weisberg D S(2007) Childhood origins of adult resistance to science. Science, 316(5827): 996-997.

Böhme, K (2002) Much ado about evidence: reflections from policy making in the European Union. Planning Theory and Practice, 3(1): 98-101.

Bourdieu P (1992) The logic of practice. Polity Press, Oxford.

Cabinet Office (1999) Modernising government. Cm 4310, Stationary Office, London.

Capra F (2003) The hidden connections. Flamingo, London.

CEC (Commission of the European Community) (2001) Governance in the EU: a white paper. COM (2001) 428 final. European Commission, Brussels.

Davoudi S (2006) Evidence-based planning: rethoric and reality. DISP 165(42): 14-24.

Denham A, Garnett M (1996) The nature and impact of think tanks in contemporary Britain. In Kandiah M D, Seldon A (eds.) Ideas and think tanks in contemporary Britain. Frank Cass, London, vol 1: 43-61.

Fainstein S, Campbell S (eds.) (1996) Readings in urban theory. Blackwell Publishers, London.

Faludi A (1973) Planning theory. Pergamon Press, Oxford. 
Ferrão J (2007) 20 por cento do País não tem dono Entrevista, Jornal Expresso, 07.07.2007.

Flyvbjerg B (2002) Bringing power to planning research: one researcher"s praxis story. Journal of Planning Education and Research, 21(4): 353-366.

Flyvbjerg B (1998) Rationality and power (morality and society) Univeristy of Chicago Press.

Foucault M (1991) Questions of method. In Burchell G, Gordon C, Miller P (eds) The foucault effect: studies in governmentality. Harvester Wheatsheaf, London: 73-86.

Friedmann J (1987) Planning in the public domain: from knowledge to action. Princton University Press.

Forrester J (1989) Planning in the face of power. University of California Press.

Giddens A (1986) The constitution of society: outline of the theory of structuration. Polity Press. Oxford.

Goss S (1999) Managing Working with the Public in Local Government. Kogan Page Ltd.

Goss S (2001) Making Local Governance Work: Networks, Relationships and the Management of Change (Government Beyond the Centre) Palgrave MacMillan.

Hall P (2002): Cities of Tomorrow (3rd. Edition). Oxford: Blackwell.

Hajer M (1995) Politics on the move: the democratic control of the design of sustainable technologies. Knowledge and Policy, 8(4): 26-39.

Healy A (2002) Commentary: evidence-based policy-the latest form of inertia and control? Planning Theory \& Practice, 3(1): 97-98.

Healey P (1997) Collaborative planning: shaping places in fragmented societies. Macmillan Press, London.

Hofstede G (1991) Cultures and Organizations: Software of the Mind. HarperCollins Publishers Ltd.

Jensen O B, Richardson T (2000) Discourses of mobility and polycentric development : a constested view of European spatial planning. European Planning Studies. 8(4): 503-520.

Leicester G (2002) Evidence-based Policy http://www.publicnet.co.uk/publicnet/fe000725.htm [Acedido em 2 de Outubro 2007].

Lindblom C E (1959) The science of "muddling through". Public Administration Review, 19: 79-88.

OED (1998) Oxford English Dictionary. Clarendon Press, Oxford.

Powell W, DiMaggio P (Eds.) (1991) The new institutionalism in organizational analysis. University of Chicago Press.

Solesbury W (2002) The ascendancy of evidence. Planning Theory and Practice, 3(1): 90-96.

Shulock N (1999) "The Paradox of Policy Analysis: If I's Not Used, Why Do We Produce So Much Of It?," Journal of Policy Analysis and Management, Vol. 18.

Taylor N (1998) Urban planning theory since 1945. Sage, London.

Urban Institute (ed.) (2003) The case for evidence-based policy: beyond ideology, politics and guesswork. Urban Institute Press.

Weiss C H (2001) What kind of evidence in evidence-based policy? Paper presented to third international, inter-disciplinary evidence-based policies and indicator systems conference, July. University of Durham.

Weiss C H (ed) (1977) Using social research in public policy making. Lexington, Massachusetts.

Young K, Ashby D, Boaz A, Grayson L (2002) Social science and the evidence-based policy movement. Social Policy and Society, 1(3): 215-224. 